\title{
Recovery cycle of the Hoffmann reflex of tobacco smokers and nonsmokers: relationship to plasma nicotine and cotinine levels
}

\author{
E.F.Domino ${ }^{1}$, C.Kadoya ${ }^{1,2}$, S. Matsuoka ${ }^{2}$ \\ ${ }^{1}$ Department of Pharmacology, University of Michigan, Ann Arbor, Michigan, USA \\ ${ }^{2}$ Department of Neurosurgery, University of Occupational and Environmental Health, Kitakyushu, Japan
}

Received: 15 November 1993/Accepted in revised form: 5 April 1994

\begin{abstract}
Ten normal adult tobacco smokers and 10 nonsmoking volunteers $20-31$ years of age were the subjects of this study. The tobacco smokers all had a history of daily tobacco smoking. They were asked to stop smoking for 12 hours prior to testing. The Hoffmann $(\mathrm{H})$ reflex and its recovery cycle were measured on different days before and just after smoking one nonfiltered $0 \mathrm{mg}$, low $(0.27 \mathrm{mg})$, or high $(2.16 \mathrm{mg})$ nicotine containing cigarette in a randomized order. Blood samples were drawn immediately after the $\mathrm{H}$ reflex recordings in the tobacco smokers. The blood samples were centrifuged, the plasma removed, frozen, and later assayed for nicotine and cotinine levels.

Nonsmokers compared to tobacco smokers before smoking only had a tendency for enhanced amplitude of the recovery cycle. After smoking the nicotine containing cigarettes, the tobacco smokers had a depression of the amplitude of the $\mathrm{H}$ reflex recovery cycle. The amplitude of the $\mathrm{H}$ reflex recovery cycle at $160 \mathrm{~ms}$ was reduced. This decreased significantly with increasing plasma nicotine and cotinine concentrations. Individual differences were marked.

The data obtained are consistent with evidence in animals that nicotine and tobacco smoke stimulate Renshaw inhibitory neurons in the spinal cord, either directly or indirectly which leads to a skeletal muscle relaxant effect.
\end{abstract}

Key words: Hoffmann reflex, Tobacco smoking; recovery cycle, plasma nicotine, plasma cotinine

The Hoffmann $(\mathrm{H})$ reflex is the electrophysiological equivalent of the ankle jerk that allows measurement of its recovery cycle. Inasmuch as the ankle jerk is easy to elicit clinically, the $\mathrm{H}$ reflex equivalent is used primarily as a research tool. The H reflex recovery cycle provides an objective measure of the excitability of the alpha-motoneu-

Correspondence to: E.F.Domino, Department of Pharmacology, M6414 Medical Science BIdg. I, University of Michigan, Ann Arbor, MI 48109-0626, USA ron pool in the spinal cord [1-3]. This technique has been used to study a variety of pharmacological agents [4-6] including nicotine and tobacco smoking $[7,8]$ in human volunteers. The purpose of the present study was to compare the recovery cycle of normal nonsmokers and tobacco smokers before and after the latter smoked various cigarettes of varying nicotine content. It was postulated that normal nonsmokers would have a slightly enhanced $\mathrm{H}$ reflex recovery cycle compared to tobacco smokers. Furthermore, it was postulated that depression of the $\mathrm{H}$ reflex recovery cycle would be positively correlated with plasma nicotine levels because nicotine stimulates Renshaw inhibitory neurons. This report describes the results obtained which confirm both hypotheses. The clinical relevance of a slight depression of the $\mathrm{H}$ reflex in tobacco smokers is that they have a skeletal muscle relaxant effect compared to nonsmokers.

\section{Subjects and methods}

All procedures involving experiments on human subjects were done in accord with the ethical standards of the Helsinki Declaration of 1975. Two separate groups of healthy Japanese subjects were studied. The first were nonsmokers and the second tobacco smokers. Although 12 nonsmokers were selected, two had very poor $\mathrm{H}$ reflexes and hence 10 were actually studied. They varied in age from 23 to 31 years with a mean of 25.9 years. Three were women and 7 were men. Ten normal tobacco smokers who inhaled and smoked at least $1 / 2$ pack of cigarettes or more per day were also studied. They varied in age from 20 to 31 with a mean of 22.8 years. Two were women and 8 were men. The subjects were asked to stop smoking the night before so they were deprived of cigarette smoking for about $12 \mathrm{~h}$ at the time of each experiment. They were recruited by word of mouth and paid a nominal remuneration for their time and participation.

\section{H reflex recovery cycle}

The methods used were similar to those described by Hugon [9]. Each subject was placed in a supine position in a relaxed state with the right leg draped over the side of the bed in order to measure skeletal muscle contraction. The limb was restrained appropriately. 
A Nicolet Pathfinder I was used in this study. The amplifier bandpass was 75 to $1500 \mathrm{~Hz}$. The first stimulus (S1) was applied to the left popliteal space for stimulating transcutaneously the posterior tibial nerve with a bipolar electrode. The cathode was placed centrally and the anode distally. A square wave pulse of $0.5 \mathrm{~ms}$ every $2 \mathrm{~s}$ was applied via the skin electrodes. The voltage amplitude of the subject's electromyographic response of the calf (soleus) muscle was recorded as the direct muscle ( $\mathrm{M}$ ) response. At the site of maximal response, a bipolar EMG electrode was placed over the soleus muscle with a ground between the stimulating and the recording electrodes. The stimulating and recording electrodes were placed so that a maximal $\mathrm{H}$ response was obtained with a minimal $\mathrm{M}$ response from the normally relaxed soleus muscle. The Nicolet was programmed to provide 16 channels of data. Channel 1 always displayed the first $\mathrm{H} 1$ response as the control. The other 15 channels displayed additional $\mathrm{H} 2 / \mathrm{H} 1$ responses at $20 \mathrm{~ms}$ intervals. The second stimulus (S2) was elicited at $60,80,100,120,140,160,180,200$, etc. ms following S2. The data obtained were expressed as the ratio of the amplitude of $\mathrm{H} 2$ to that of $\mathrm{H} 1$ response at different msec intervals in order to determine the recovery cycle of the $\mathrm{H}$ reflex. The $\mathrm{H} 2 / \mathrm{H} 1$ ratio is an index of the local alpha motoneuron pool excitability for the interval between the S1 and S2 stimuli [1-3].

\section{Experimental design}

Subjects from both groups were asked to come to the laboratory in the morning between 08.30 and $10.00 \mathrm{~h}$ after a light breakfast. There were no restrictions on food or drinks. Nonsmokers were asked to avoid smokers. Tobacco smokers were asked not to smoke overnight. Each nonsmokers was asked to simulate tobacco smoking by sucking air through a sham cigarette. Two presham and two postsham $\mathrm{H}$ reflex recovery cycles were determined for each nonsmoker.

Each tobacco subject, approximately $12 \mathrm{~h}$ after the last tobacco cigarette smoked, was asked to smoke three different nonfiltered cigarettes on different days in the laboratory. The cigarettes contained: 1) no $(0 \mathrm{mg})$, low $(0.27 \mathrm{mg})$, or high nicotine $(2.16 \mathrm{mg})$. Each tobacco smoker smoked the cigarettes at his or her normal method of inhalation and duration of 5-8 min. Two presmoking and two postsmoking $\mathrm{H}$ reflex recovery cycles were determined for each subject. Blood samples were drawn into heparinized tubes after the $H$ reflex recovery cycle was determined before and after tobacco smoking. The blood was centrifuged and the plasma removed and frozen until assay.

\section{HPLC assay of nicotine and cotinine}

Plasma nicotine and cotinine were determined simultaneously using the high performance liquid chromatography (HPLC) assay of Hariharan et al. [10]. The samples were vortexed for $3 \mathrm{~s}$ and centrifuged for $5 \mathrm{~min}$ at $1,661.3 \mathrm{~g}$. The plasma was placed into clean Teflon tubes and frozen at $-20^{\circ} \mathrm{C}$. After thawing, $50 \mu \mathrm{l}$ of the internal standard, $\mathrm{N}$-ethyl nicotine, was added to each $1 \mathrm{ml}$ aliquot of sample. In order to remove plasma proteins, $1.5 \mathrm{ml}$ of a $10 \%$ trichloracetic acid (TCA) solution was added to each sample. The samples were vortexed for $3 \mathrm{~s}$ immediately after adding the TCA solution to ensure that no nicotine or cotinine remained in the precipitated protein. The samples were then centrifuged for $30 \mathrm{~min}$ at $461,432.2 \mathrm{~g}$ and the aqueous layer decanted into clean Teflon tubes.

In order to remove aqueous acid impurities, $300 \mu \mathrm{l}$ of $12.5 \mathrm{M}$ $\mathrm{KOH}$ was added to each sample. Nicotine and cotinine were then extracted with $5500 \mu \mathrm{l}$ of methylene chloride by shaking the samples for $30 \mathrm{~min}$. The samples were then centrifuged for $5 \mathrm{~min}$ at $1,661.3 \mathrm{~g}$. The aqueous $\mathrm{KOH}$ layer was aspirated off and $3 \mathrm{ml}$ of $0.5 \mathrm{M} \mathrm{HCl}$ was added to each tube. After shaking the samples for $10 \mathrm{~min}$ and then centrifuging for $5 \mathrm{~min}$ at $1,661.3 \mathrm{~g}$, the methylene chloride layer was removed. An additional $300 \mu \mathrm{l}$ of $12.5 \mathrm{M} \mathrm{KOH}$ and $5,000 \mu \mathrm{l}$ of methylene chloride were added and the samples shaken for $10 \mathrm{~min}$

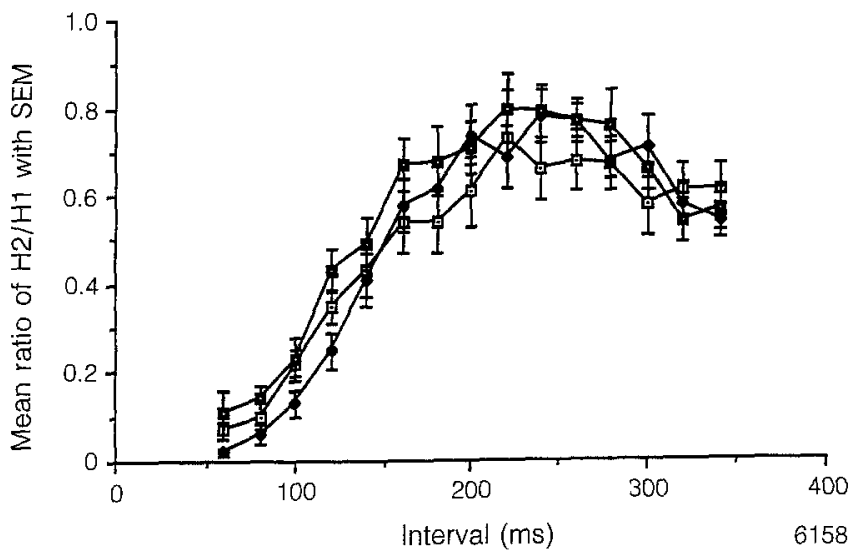

Fig. 1. Reproducibility of the mean recovery cycle of the Hoffmann reflex of ten tobacco smokers in the morning twelve hours after stopping smoking on three different occasions. $-[\cdot]-$ Free; $-\longrightarrow$ low; - - high

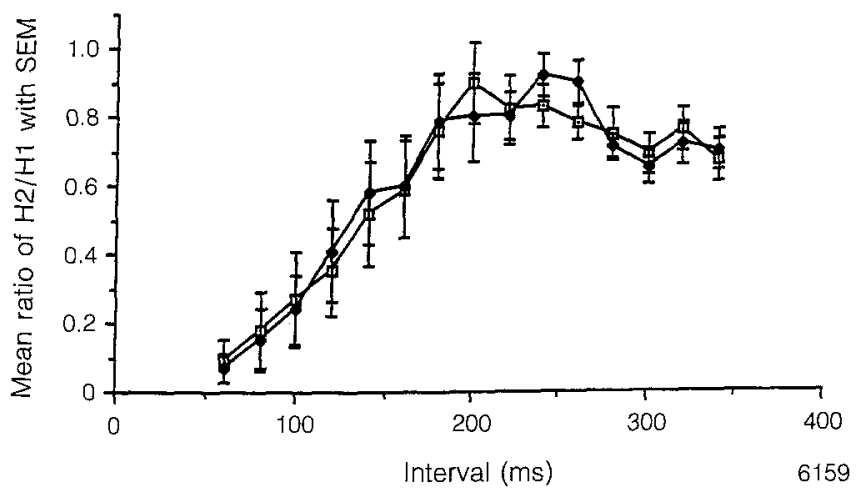

Fig.2. The mean recovery cycle of the Hoffmann reflex of ten nonsmokers does not change after sham smoking. $-\square-$ Pre; post

and centrifuged for $5 \mathrm{~min}$ at $1,661.3 \mathrm{~g}$. The aqueous $\mathrm{KOH}$ layer was removed and $200 \mu \mathrm{l}$ of $0.025 \mathrm{M} \mathrm{HCl}$ washed in methylene chloride was added to each sample. The samples were evaporated using $\mathrm{N}_{2}$ gas and a warm water bath until only the nicotine and cotinine salts remained. An excess of citric acid was added to a final $\mathrm{pH}$ of 4.5 . The reconstituted samples were vortexed for one min and centrifuged for an additional one min at $1,661.3 \mathrm{~g}$. The samples, along with $\mathrm{a}_{2} \mathrm{O}$ blank and three standards, were loaded into the autoinjector. The HPLC unit consisted of a pump (Model 655A, Hitachi), a detector (Model 655-A23, Hitachi), and a flow cell with a path length of $5 \mathrm{~mm}$. A dual channel integrator (Model D-200, Hitachi) was used. The flow rate was held at $1.5 \mathrm{ml} \cdot \mathrm{min}^{-1}$. The detector was set at a wave length of $256 \mathrm{~nm}$. The resulting nicotine and cotinine peaks were then compared with the standards and the internal standard peaks.

\section{Results}

Reproducibility of the mean recovery cycle of the H reflex in tobacco smokers before smoking

On three different occasions the same 10 tobacco smokers were asked to stop smoking overnight (approximately $12 \mathrm{~h}$ of withdrawal) and to come to the laboratory in the morning. Their $\mathrm{H}$ reflex recovery cycle was obtained 


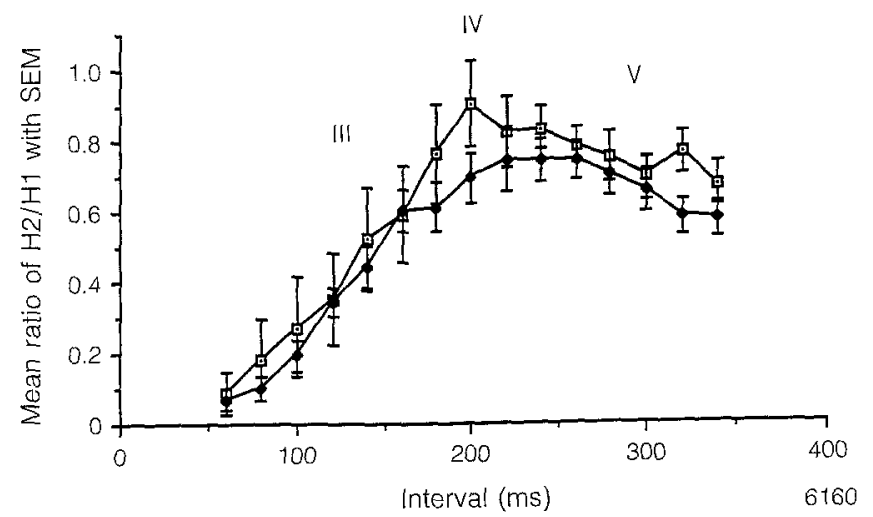

Fig. 3. Mean recovery cycle of the Hoffmann reflex in nonsmokers and tobacco smokers before smoking in the A.M. The overall mean data of Fig. 1 for the tobacco smokers are compared to the nonsmokers before tobacco or sham smoking. The three phases of the $\mathrm{H}$ reflex recovery cycle using the terminology of Hugon et al. [22] are labelled as $I I I, I V$ and $V$. - - - - Nonsmokers; $-\longrightarrow$ smokers

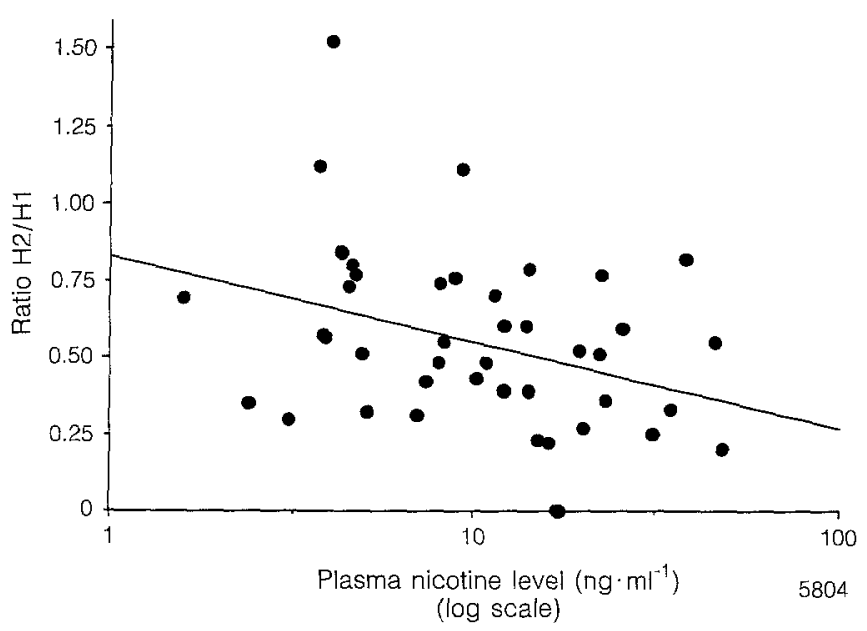

Fig. 4. Correlation coefficient of plasma nicotine and the ratio of the $\mathrm{H} 2 / \mathrm{H} 1$ amplitude in tobacco smokers at $160 \mathrm{~ms}$. Note that in spite of the marked variability there is a negative correlation $(r=-0.346)$ which is statistically significant $(P=0.023 ; \mathrm{y}=0.829-0.281 \mathrm{x})$. Each dot in this and the subsequent figure represents one experimental value from one subject studied on one day

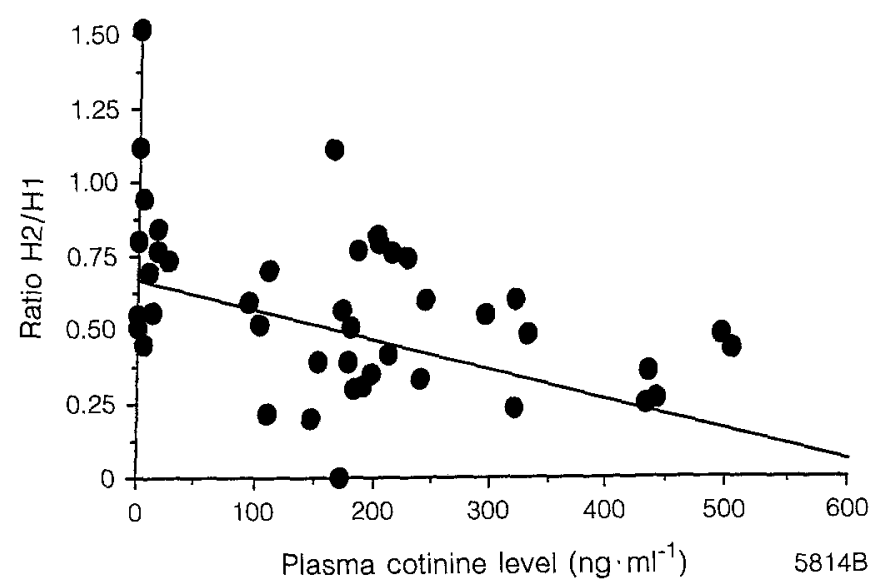

Fig. 5. Correlation coefficient of plasma cotinine and the ratio of the $\mathrm{H} 2 / \mathrm{H} 1$ amplitude in tobacco smokers at $160 \mathrm{~ms}$. Again, in spite of the variability, there is a negative correlation $(r=-0.43)$ which is statistically significant $(P=0.004 ; \mathrm{y}=0.665-1.02 \mathrm{e}-3 \mathrm{x})$ twice before smoking. The data were averaged for all 10 smokers and plotted, as illustrated in Fig. 1. The same group of subjects were given on different days each week a nicotine free, a low, and a high nicotine cigarette to smoke after obtaining control before smoking recovery cycles for the $\mathrm{H}$ reflex. It can be seen that over a period of several weeks the mean recovery cycle for each of three different days is very similar. The standard errors usually overlapped.

\section{Mean recovery cycle of the $H$ reflex in nonsmokers before and after sham smoking}

Ten nonsmokers were asked to come to the laboratory once and sham smoke by puffing on a straw filled with cotton to mimic a tobacco smoker. The mean $\mathrm{H}$ reflex recovery cycle before and after sham smoking did not change, as illustrated in Fig. 2. The S. E. completely overlapped and there were no statistically significant differences at any of the time intervals.

Comparison of the mean recovery cycle of the $H$ reflex in nonsmokers and tobacco smokers before smoking in the morning

The mean $\mathrm{H}$ reflex recovery cycle of 10 nonsmokers and 10 tobacco smokers is illustrated in Fig. 3. Although tobacco smokers at most intervals had a lower mean amplitude of the $\mathrm{H} 2 / \mathrm{H} 1$ response compared to the nonsmokers, the S.E. usually overlapped and hence the differences were not statistically significant. A trend analysis indicated that 13 out of 15 times the mean amplitude of the $\mathrm{H} 2 / \mathrm{H} 1$ response was slightly greater in the nonsmokers.

\section{Effects of tobacco smoking on the recovery cycle of the $H$ reflex and its relationship to plasma nicotine and cotinine levels in tobacco smokers}

As reported previously for tobacco smokers [8], smoking a nicotine free cigarette had no effect on the $\mathrm{H} 2 / \mathrm{H} 1$ response. After smoking a high nicotine containing cigarette, there was a reduction of the $\mathrm{H} 2 / \mathrm{H} 1$ response. This was not a dramatic effect in all tobacco smokers. Some subjects only showed a slight tendency for reduction. Nevertheless, the mean data of all 10 smokers showed a decrease in the amplitude of the $\mathrm{H}$ reflex recovery cycle (see Fig. 3). Of interest is the fact that the early portion (phase III), the midportion of maximum recovery of $\mathrm{H} 2 / \mathrm{H} 1$ (phase IV), and the late inhibition (phase V) of the recovery cycle was depressed (see Fig. 3). Smoking a low nicotine cigarette had much less of an effect on the recovery cycle of the $\mathrm{H}$ reflex. A correlation coefficient between the amplitude of the $\mathrm{H} 2 / \mathrm{H} 1$ reflex and plasma nicotine and cotinine levels and tobacco smoking of all three different cigarettes was determined. The data are illustrated in graph form in Figs. 4 and 5. The number of data points shown vary and, in some cases, overlap. 


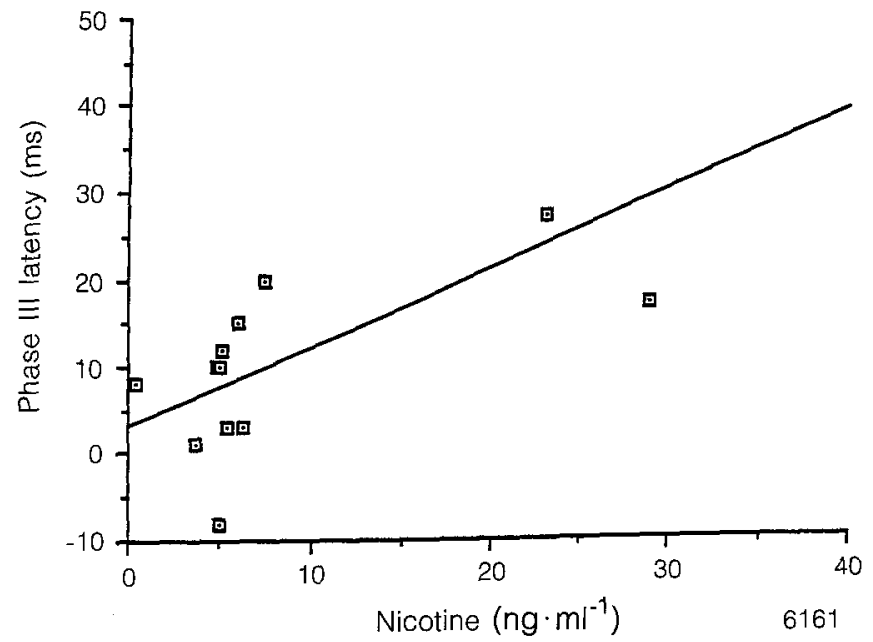

Fig.6. Correlation of increase in plasma nicotine and prolongation of initial phase III $\mathrm{H} 2 / \mathrm{H} 1$ recovery in tobacco smokers post-pre smoking. The data of 10 tobacco smokers smoking high and low nicotine cigarettes are plotted. Thirteen of the 20 possible data points that had a change in plasma nicotine were used in this analysis, $r=0.777, P=0.006, \mathrm{y}=2.88+0.902 \mathrm{x}$

There is a negative correlation between the ratio of the $\mathrm{H} 2 / \mathrm{H} 1$ recovery cycle at $160 \mathrm{~ms}$ and plasma nicotine levels. When plasma nicotine levels were plotted logarithmically on the $\mathrm{x}$ axis and the ratio of the $\mathrm{H} 2 / \mathrm{H} 1$ reflex plotted arithmetically on the y axis a linear relationship was observed with a correlation coefficient $r=0.346$, $P$ value $=0.023$. The data are presented in graph form in Fig. 4. There was also a significant relationship between the plasma level of cotinine with respect to the recovery cycle of the Hoffmann reflex at $160 \mathrm{~ms}$. When plasma cotinine levels were plotted arithmetically on the $\mathrm{x}$ axis and the $\mathrm{H} 2 / \mathrm{H} 1$ ratio on the $\mathrm{y}$ axis the correlation coefficient was $r=0.43, P$ value $=0.0036$. These data are presented in graph form in Fig.5. Although both arithmetic and logarithmic plots were made for both plasma nicotine and plasma cotinine, the significant correlations obtained were the logarithm of plasma nicotine and the arithmetic value of plasma cotinine. Perhaps these differences are related to the differing plasma half lives of each compound.

\section{Correlation between the prolongation of phase III depression of the H reflex and the change in plasma nicotine after tobacco smoking}

The latency to onset of the first observable $\mathrm{H} 2 / \mathrm{H} 1$ response was correlated with the change $(\Delta)$ in nicotine plasma levels (after minus before smoking) in the tobacco smokers after they smoked either high or low nicotine containing cigarettes. The data obtained are plotted in Fig.6. There was a highly significant correlation $(r=0.777, P=0.006)$ between these two variables in tobacco smokers.

\section{Discussion}

The data obtained support and extend previous findings on the effects of tobacco smoking and $0.8-1 \mathrm{mg}$ i.v. nicotine on the $\mathrm{H}$ reflex recovery cycle $[7,8]$. In the present study, there was no significant correlation between plasma levels of nicotine pre and post smoking one cigarette vs the plasma cotinine levels pre and post in the tobacco smokers. This would be expected because Benowitz et al. [11] and Fayerabend et al. [12] have shown that nicotine blood levels have a log linear decline of with a terminal half life of about $2 \mathrm{~h}$. In contrast, the mean terminal half life of cotinine is $18 \mathrm{~h}$ with a range of $11-37 \mathrm{~h}$ [13]. One would not expect any correlation between nicotine levels taken with a short half life compared to the very long half life of cotinine since multiple tobacco cigarettes containing nicotine were smoked over many hours the day previously.

Cotinine is a relatively inactive metabolite of nicotine. There are no data on the direct effects of cotinine on the $\mathrm{H}$ reflex. However, cotinine does have pharmacologic effects. Yamamoto and Domino [14] reported that doses of cotinine equal to $10 \mu \mathrm{g} \cdot \mathrm{kg}^{-1}$ of nicotine had no effect on EEG or behavior of deeply sleeping cats. However, when a thousand times larger dose of cotinine $\left(10 \mathrm{mg} \cdot \mathrm{kg}^{-1} \mathrm{i} . \mathrm{v}\right.$. $)$ was given, the animals showed transient EEG activation and behavioral arousal. The latter dose of cotinine had no effect on blood pressure. On the other hand, supramassive doses of cotinine in the order of $25 \mathrm{mg} \cdot \mathrm{kg}^{-1}$ i. v. produced a slight fall in blood pressure. These doses of cotinine also produce brief episodes of EEG activation and arousal [14]. In view of the fact that cotinine has $1 / 1000$ or less the potency of nicotine in altering the EEG or arterial blood pressure, it is probable that cotinine itself does not have any significant pharmacological effect in suppressing the recovery cycle of the Hoffmann cycle. It is unlikely that there is a dissociation between the dose of cotinine that acts on the Renshaw inhibitory system in the spinal cord vs the dose of cotinine that causes EEG and behavioral arousal and cardiovascular effects. Thus, we are left with the dilemma why there should be a statistically significant relationship between plasma cotinine levels and the recovery of the Hoffmann reflex. Perhaps cotinine simply is reflecting the fact that tobacco smokers who had inhaled nicotine in tobacco smoke the day previously still had enough nicotine in their body to produce a reduction in the Hoffmann reflex recovery cycle or that cotinine does have pharmacological actions in its own right. Multiregression analysis would be a valuable technique to pursue this issue further.

The $\mathrm{H}$ reflex recovery cycle is a measure of the excitability of the alpha-motoneuron pool in the spinal cord which mediates the ankle jerk. This excitability is controlled by peripheral, segmental and central mechanisms of the nervous system. Peripheral afferents have very important effects on the recovery cycle of the $\mathrm{H}$ reflex which can be altered by topical local anesthetics applied to the skin [15]. Whether the effects of inhaled nicotine are directly on the spinal cord or inputs from peripheral sites is a subject of future study. There is no question that nicotine itself directly stimulates Renshaw inhibitory 
neurons in the spinal cord [16-19]. Ginzel [20-21] has provided evidence that nicotine also excites a variety of peripheral sites including a large variety of peripheral chemoreceptors as well as sensory receptors including the muscle spindle. These additional inputs could stimulate Renshaw inhibitory neurons and thus may indirectly act to suppress the recovery cycle of the $H$ reflex.

As illustrated in Fig. 3, there are several phases of inhibition as well as excitation of the $\mathrm{H}$ reflex. There is an early inhibition (phase III) followed by a late facilitation (phase IV) and a subsequent late inhibition (phase V) using the terminology of Hugon et al. [22]. Phase III inhibition was prolonged in the tobacco smokers. Its prolongation correlated with plasma $\Delta$ nicotine. The electrical stimulus was purposely adjusted to be liminal for $M$ responses and supraliminal for $\mathrm{H}$ responses via group IA afferents. Such a stimulus is also supraliminal for IB fibers which have central inhibitory effects on homonymous motor neurons. The $\mathrm{H} 1$ response results in a soleus muscle twitch that stretches the muscle and causes the muscle spindles to fire transiently and send an afferent volley onto alpha-motor neurons, again via group IA. Shortly after the muscle twitch, group IB afferents from the tendon organs send inhibitory inputs via Renshaw cells onto alpha-motor neurons. These alterations in afferent volleys induce a central excitatory-inhibitory effect and cause phase IV and V changes in the recovery cycle as described by Bouaziz et al. [23]. Such an input is thought to induce sustained presynaptic inhibition as a possible mechanism for the late phase $\mathrm{V}$ inhibition. There is data, at least in the monkey, that bicuculine reduces the late inhibitory response and oxyaminoacetic acid increases it. It has been shown by Curtis and Ryall [18] and Ryall [19] that recurrent Renshaw interneurons represent an early discharge of cholinergic nicotinic cells while their long lasting slow discharge is a muscarinic cholinergic phenomenon. Atropine in a dose of $3 \mathrm{mg} \cdot \mathrm{kg}^{-1} \mathrm{i}$. v. in monkeys suppresses the late inhibition (V) without significantly changing the early inhibition (III). On the basis of the effects of atropine on muscarinic synapses, Hugon [9] concluded that Renshaw cell activity has a role in the development of late inhibition. In the monkey, Bouaziz and Hugon (quoted by Hugon [9]) have shown that dihydro-beta-erythroidine, a nicotinic cholinergic antagonist, suppresses the major part of early inhibition except the very beginning (phases I and II) which apparently is caused by $1 \mathrm{~B}$ inhibitory afferents. The role of nicotinic cholinergic recurrent inhibition in early inhibition is generally accepted. Our data that higher plasma concentrations of nicotine in the tobacco smokers prolonged phase III inhibition are consistent with such a role. Surprisingly, even the late inhibition (phase V) was depressed in tobacco smokers inasmuch as this component is thought to be mediated by a muscarinic cholinergic component. Perhaps nicotine that is inhaled and enters the circulation releases endogenous acetylcholine from neurons in the spinal cord which may act through a muscarinic mechanism. Acetylcholine is released by nicotine in the cerebral cortex [24] so such a mechanism in the spinal cord is certainly plausible.
The present research confirms the fact that humans who smoke tobacco have skeletal muscle relaxant effects. This has been known for many years and has been described in many textbooks of pharmacology. The present research shows the correlation of the $\mathrm{H}$ reflex recovery cycle with plasma nicotine and cotinine levels. Webster [25] reported that tobacco smoking reduced spasticity in a patient with progressive familial spastic paraplegia as measured quantitatively using passive motion resistance. It would be of interest to do additional studies with nicotine gum and patches to determine whether there is any significant tachyphylaxis or tolerance with continued nicotine administration.

Acknowledgement. Supported in part by NIDA grant DA-07226.

\section{References}

1. Táboríková H, Sax DS (1968) Motoneurone pool and the H reflex. J Neurol Neurosurg Psychiatry 31: 354-361

2. Gassel MM (1970) Critical review of evidence concerning longloop reflexes excited by muscle afferents in man. J Neurol Neurosurg Psychiatry 33: 358-362

3. Masland WS (1972) Facilitation during the H-reflex recovery cycle. Arch Neurol 26:313-319

4. Crayton JW (1980) The effect of diazepam on the spinal monosynaptic $(\mathrm{H})$ reflex in man. Neuropharmacology 19: 915-918

5. Metz J, Holcomb HH, Meltzer HY (1982) Effect of chlorpromazine on H-reflex recovery curves in normal subjects and schizophrenic patients. Psychopharmacology 78: 342-345

6. Metz J, Holcomb HH, Meltzer HY (1988) Effect of 5-hydroxytryptophan on $\mathrm{H}$-reflex recovery curves in normal subjects and patients with affective disorders. Biol Psychiatry 23: 602611

7. Gassel MM (1973) An objective technique for the analysis of the clinical effectiveness and physiology of action of drugs in man. In: Desmedt $J$ (ed) New developments in electromyography and clinical neurophysiology, vol 3. Karger, Basel, pp 342-359

8. Kadoya C, Matsuoka S, Domino EF (1993) Effects of tobacco smoking on the Hoffmann $(\mathrm{H})$ reflex. Neuropsychopharmacol 9: 233-238

9. Hugon M (1973) Methodology of the Hoffmann reflex in man. In: Desmedt JE (ed) New developments in electromyography and clinical neurophysiology, vol 3. Karger, Basel, pp 277-293

10. Hariharan M, Van Noord T, Greden FJ (1988) A high-performance liquid-chromatographic method for routine simultaneous determination of nicotine and cotinine in plasma. Clin Chem 34: 724-729

11. Benowitz NL, Jacob P III, Jones RT, Rosenberg J (1982) Interindividual variability in the metabolism and cardiovascular effects of nicotine in man. J Pharmacol Exp Ther 221: 368-372

12. Fayerabend C, Ings RM, Russell MAH (1985) Nicotine pharmacokinetics and its application to intake from smoking. Br J Clin Pharmacol 19: 239-247

13. Benowitz NL, Kuyt F, Jacob P III, Jones RT, Osman AL (1983) Cotinine disposition and effects. Clin Pharmacol Ther 309: 139142

14. Yamamoto K, Domino EF (1965) Nicotine-induced EEG and behavioral arousal. Int J Neuropharmacol 4:359-373

15. Sabbahi M, Deluca CJ (1981) Topical anesthesia: H-reflex recovery changes by desensitization of the skin. Electroencephalogr Clin Neurophysiol 52: 328-335

16. Eccles JC, Fatt P, Koketsu K (1954) Cholinergic and inhibitory synapses in a pathway from motor-axon collaterals to motoneurons. J Physiol (Lond) 126:524-562 
17. Ueki S, Koketsu K, Domino EF (1961) Effects of mecamylamine on the Golgi recurrent collateral-Renshaw cell synapse in the spinal cord. Exp Neurobiol 3: 141-148

18. Curtis RD, Ryall RW (1964) Nicotine and muscarinic receptors of Renshaw cells. Nature 203: 652-653

19. Ryall W (1970) Renshaw cell mediated inhibition of Renshaw cells: Patterns of excitation and inhibition from impulses in motor axon collaterals. J Neurophysiol 33: 257-270

20. Ginzel KH (1967) Introduction to the effects of nicotine on the central nervous system. Ann NY Acad Sci 142: 101-120

21. Ginzel KH (1967) The action of nicotine and smoking on reflex pathways. Austr J Pharmacol 48 [Suppl 52]: 30-33

22. Hugon M, Fagni L, Seki K (1983) Deep sea diving: Human performance and motor control under hyperbaric conditions with inert gas. In: Desmedt JE (ed) Motor control mechanisms in health and disease. Adv Neurol 39: 829-848

23. Bouaziz Z, Bouaziz M, Hugon M (1983) Modulation of soleus electromyogram by electrical stimulation of medial gastrocnemius nerve in man. Electromyograph 15: 31-42

24. Armitage AK, Hall GH, Sellers CM (1969) Effects of nicotine on electrocortial activity and acetylcholine release from the cat cerebral cortex. Br J Pharmacol 35: 152-160

25. Webster DD (1964) The dynamic quantification of spasticity with automated integrals of passive motion resistance. Clin Pharmacol Ther 5: 900-908

\section{Note added in proof.}

Keenan et al. (Clin Pharmacol Ther 55: 581-590, 1994) reported that cotinine is behaviorally active in abstinent smokers at serum concentrations similar to those obtained through daily cigarette smoking. 